\title{
Recria de bovinos de corte mantidos em pastagem de aveia preta com diferentes ofertas de forragem, com e sem suplementação
}

\author{
[Rearing of beef cattle grazing oats with different forage allowances, with or \\ without supplementation] \\ L.F.G. Menezes ${ }^{1}$, T. Venturini ${ }^{2}$, F. Kuss ${ }^{1}$, C.E. Kruger $^{2}$, R. Ronsani ${ }^{2}$, W. Paris ${ }^{1}$, \\ R.R. Biesek ${ }^{2}$, S.J. Pontes ${ }^{2}$ \\ ${ }^{1}$ Universidade Tecnológica Federal do Paraná - Campus Dois Vizinhos, PR \\ ${ }^{2}$ Aluno de graduação - Universidade Tecnológica Federal do Paraná - Campus Dois Vizinhos, PR

\section{RESUMO}

O objetivo deste estudo foi avaliar o desempenho de bezerros recebendo ou não suplemento energético, mantidos em pastagem de aveia preta (Avena strigosa Schreb) manejada sob duas ofertas de forragem. Foram utilizados 16 animais do grupamento genético Composto Marchangus Z (1/4 Marchigiana 1/4 Angus $1 / 2$ Nelore), com oito meses de idade, castrados, e com peso médio inicial de $200 \mathrm{~kg}$. O delineamento experimental utilizado foi o inteiramente ao acaso, em um fatorial $2 \times 2$ (duas ofertas de forragem $x$ dois manejos alimentares - com e sem suplementação de milho moído). Não houve interação significativa entre oferta e suplementação para nenhuma das variáveis. A oferta de forragem real ficou próxima do estipulado para 6 e $10 \%$ (5,95\% e $9,07 \%$, respectivamente). A oferta de $6 \%$ apresentou maior porcentagem de folha $(57,0$ contra $30,4 \%)$, menor porcentagem de colmo $(43,0$ contra $69,6 \%)$ e, consequentemente, maior relação folha/colmo $(1,45$ contra 0,45$)$, resultando em pastagens de melhor qualidade $(\mathrm{PB}=20,0$ contra $13,6 \%)$ na menor oferta. A taxa de acúmulo diária foi maior $(\mathrm{P}<0,05)$ para oferta de forragem de $6 \%$ (34,2kg de MS/ha/dia) em relação à oferta de $10 \%(28,1 \mathrm{~kg}$ de MS/ha/dia). A suplementação proporcionou maior ganho de peso médio diário $(0,749$ contra $0,594 \mathrm{~kg} / \mathrm{dia})$ na recria de bezerros em pastagem de aveia preta IPR-61.

Palavras-chave: Avena sativa, bezerros, desempenho animal, IPR-61

\begin{abstract}
The objective of this study was to evaluate the performance of calves fed supplemented energy or not maintained in oat (Avena strigosa Schreb) managed under two forage allowances. Sixteen Marchangus (1/4 Marchigiana 1/4 Angus 1/2 Nelore) animals were used at eight months old and average initial weight of 200kg. The experimental design utilized was completely randomized in a $2 \times 2$ factorial (two forage allowances $x$ two feeding - with and without supplementation of corn). There was no significant interaction between supply and supplementation for the variables. The real forage allowance was close to the expected from 6 to $10 \%$ (5.95 and 9.07\%, respectively). The offer of 6\% shows higher percentage of leaf (57.0 versus 30.4\%), lower percentage of stem (43.0 versus 69.6\%) and, consequently, higher leaf/stem ratio (1.45 versus 0.45$)$, resulting in better forage ( $P B=20.0$ versus $13.6 \%)$, in lower offer. The accumulated rate was higher $(P<.05)$ for forage allowance of $6 \%(34.2 \mathrm{~kg}$ of $\mathrm{MS} / \mathrm{ha} /$ day $)$ in relation to the offer of $10 \%(28,1 \mathrm{~kg}$ of MS/ha/day). Supplemented animals showed higher average dairy weight $(.749$ versus $.549 \mathrm{~kg} /$ day).
\end{abstract}

Key-words: Avena sativa, calves, IPR-61, performance

Recebido em 2 de junho de 2011

Aceito em 12 de janeiro de 2012

E-mail: luismenezes@utfpr.edu.br 


\section{INTRODUÇÃO}

A alimentação de bovinos de corte, de maneira geral, é fundamentada em sistemas produtivos baseados em pastagem. Estima-se que ultrapasse 90\% o índice de animais abatidos no Brasil oriundos de sistemas de produção a pasto, fator contribuinte para tornar o país detentor do maior rebanho bovino comercial e líder em exportações de carne bovina (Anualpec, 2011).

O sistema a pasto é uma prática consolidada entre os produtores rurais na busca por aprimorar os índices produtivos de seus rebanhos, de maneira que as pastagens são responsáveis por quase toda a oferta de proteína, energia, vitaminas e minerais necessários para atender as exigências e manutenção dos animais. Tanto é assim que a utilização de pastagens anuais temperadas, como a aveia preta, é uma alternativa para obtenção de altos ganhos de peso em animais que apresentam alimentação exclusivamente a pasto (Grise et al., 2002).

Pastagens hibernais que apresentam elevado valor nutricional e alto potencial produtivo são alternativas viáveis na terminação de bovinos (Aguinaga et al., 2006). Sendo assim, deve-se levar em consideração o manejo conduzido relacionado à altura da pastagem, devido à relação com os níveis de massa de forragem e consumo dos animais.

A suplementação de animais mantidos em condições de pastejo tem como meta principal a mantença do desempenho animal quando a massa ou a qualidade da forragem torna-se um fator limitante (Santos et al., 2005). A utilização de concentrados energéticos apresenta resultados satisfatórios para compensar o desempenho dos animais no período inicial de utilização dos cereais de inverno (Frizzo et al., 2003). De maneira geral, são empregadas várias formas de suplementar esses animais nos períodos críticos mediante a utilização da suplementação proteica de baixo consumo $(1 \mathrm{~g} / \mathrm{kg}$ de PV) ou suplementos proteico-energéticos de alto consumo $(10 \mathrm{~g} / \mathrm{kg}$ de PV) (Reis et al., 2009).

A fim de expressar o máximo potencial produtivo para a característica de ganho de peso, o animal deve ter as suas exigências atendidas, entretanto, sob condições exclusivas de pastagem, o seu desempenho fica limitado pela falta de energia e/ou proteína (Nutrient..., 1996). Dessa forma, o presente trabalho tem como objetivo avaliar o desempenho de novilhos suplementados e não suplementados com concentrado energético em pastagem de aveia preta cv. IPR 61 (Avena strigosa Schreb) manejada em duas ofertas de forragem.

\section{MATERIAL E MÉTODOS}

O trabalho foi realizado na Unidade de Ensino e Pesquisa de Bovinocultura de Corte da Universidade Tecnológica Federal do Paraná (UTFPR), Campus Dois Vizinhos, situada a $25^{\circ}$, 42', 52' ' de latitude S e longitude de 53 ${ }^{\circ}, 03^{\prime}$, 94" W, a 519 metros acima do nível do mar. O solo local é o tipo latossolo vermelho distroférrico típico, e o terreno apresenta em torno de $5 \%$ de declividade média.

A pastagem foi implantada no sistema de plantio direto no dia 5 de maio de 2010. A semeadura foi realizada com $50 \mathrm{~kg}$ de semente por ha de aveia preta cv IAPAR 61 (Avena strigosa cv IAPAR $61)$ e $150 \mathrm{~kg}$ de adubo de fórmula 05-20-20. Em cobertura, foram utilizados $100 \mathrm{~kg}$ de ureia em duas aplicações (uma no início e outra no meio do período experimental).

O período de avaliação foi de 12 de junho a 28 de agosto, totalizando 76 dias. Foram utilizados 16 bovinos machos, castrados, do grupo genético Composto MarchangusZ (1/4 Marchigiana x 1/4 Angus x 1/2 Nelore), de aproximadamente oito meses de idade, com peso médio inicial de $200 \pm 34,92 \mathrm{~kg}$, como testers. O sistema de pastejo utilizado foi o intermitente, utilizando animais reguladores, de mesma idade e grupamento genético, alocados no experimento conforme a necessidade do ajuste da carga animal pela técnica "put-and-take" (Mott e Lucas, 1952). A cada 21 dias, foi realizada a pesagem individual dos animais com um período de jejum de sólidos e líquidos de 12 a 14 horas. A área experimental foi dividida em oito piquetes, com média de 0,8 ha por piquete, totalizando 6,3 ha, além de uma área de 1,5 ha onde permaneciam os animais reguladores.

O desempenho dos animais em pastejo foi avaliado pela combinação de duas ofertas de forragem com e sem o uso de suplementação energética. As ofertas de forragem pretendidas foram de 6 e 10\%. A oferta de forragem 
(OF) foi determinada conforme a equação: $\mathrm{OF}=\left\{\left[\mathrm{MF}+\left(\mathrm{TAD}^{*} \mathrm{~N}^{\circ}\right.\right.\right.$ dias $\left.)\right] / \mathrm{N}^{\circ}$ dias $\} /$ carga animal*100. O suplemento utilizado foi o grão de milho (Zea mays) triturado, oferecido na proporção de $0,8 \%$ do peso vivo, fornecido diariamente às 12 horas, em cochos alocados nos piquetes que recebiam a suplementação respeitando-se o espaçamento de cocho por animal conforme o número de animais presentes em cada período.

A massa de forragem foi determinada no início de cada período experimental, com intervalos de 21 dias entre as avaliações, pela técnica de dupla amostragem (WILM et al., 1944). Para determinação da taxa de acúmulo diário (TAD) em cada período, foram utilizadas duas gaiolas de exclusão ao pastejo por repetição, utilizandose metodologia descrita por Klingmann et al. (1943). A partir da separação botânica dos componentes da massa de forragem, proporção de lâminas foliares, colmos e material senescente ou morto, foi calculada a composição botânica da pastagem.

A determinação dos teores de proteína bruta (PB) da forragem foi realizada a partir das amostras colhidas por meio de simulação de pastejo (Gibb e Treacher, 1976), coletando-se uma amostra no mesmo dia da realização da dupla amostragem em cada um dos períodos experimentais. As amostras colhidas foram pesadas e secas em estufa a $65^{\circ} \mathrm{C}$, por 72 horas, processadas em moinho tipo Willey e encaminhadas para análise de PB de acordo com Association... (1984).

O delineamento experimental utilizado foi $\mathrm{o}$ inteiramente ao acaso, em esquema fatorial $2 \times 2$ (duas ofertas $\mathrm{x}$ dois manejos alimentares). Os dados foram submetidos à análise de variância, e aqueles que apresentaram 5\% de significância foram comparados pelo teste Tukey (SAS, 2001).

\section{RESULTADOS E DISCUSSÃO}

Não houve interação significativa entre as variáveis estudadas. Observa-se (Tab. 1) que os valores de oferta de forragem real ficaram bem próximos dos estipulados (5,95 e 9,07\%). Para que não haja limitação de consumo, a oferta de forragem deve ser três vezes maior que o consumo estimado dos ruminantes (Gibb e Treacher, 1976). Pelo (Nutrient..., 1984), o consumo estimado para animais desta categoria é de $2,5 \%$ do peso vivo e, portanto, a menor oferta pode ter limitado o desempenho animal. Já a presença do suplemento não afetou a oferta de forragem $(7,51 \%$, em média).

Segundo Pilau et al. (2005), a estrutura da pastagem sofre acentuada modificação conforme a disponibilidade de forragem utilizada. A menor oferta de forragem estimulou o perfilhamento, proporcionando maior porcentagem de folha (57\%) em relação ao colmo do que na pastagem que apresentava maior oferta $(30,4 \%$ de folhas). Da mesma forma que o observado por Pilau et al. (2005), a maior porcentagem de folhas na pastagem com oferta menor proporcionou oferta de lâminas foliares (LF) semelhantes $(4,45 \mathrm{~kg}$ de LF/100kg de PV) nos tratamentos. Segundo Holmes (1987), o consumo potencial de matéria seca estaria igualado nas duas ofertas estudadas, pois a disponibilidade de lâminas foliares é melhor preditora do consumo de matéria seca por animais em pastejo que a oferta total de forragem. Na comparação entre os tratamentos com ou sem suplemento, não houve variação da estrutura da pastagem, uma vez que a oferta manteve-se semelhante.

A utilização de altas ofertas de forragem em pastagens é necessária para evitar a redução no desempenho animal, favorecido muitas vezes pelo baixo valor nutritivo da forragem, sendo que quanto melhor a qualidade da pastagem, maior serão os ganhos de peso por animal e menor necessidade de oferta de forragem (Euclides, 2001). Essa afirmação vem de encontro ao observado no presente estudo, em que a baixa oferta de forragem foi compensada pelo seu maior valor nutritivo (20,0 contra $13,6 \%$ de proteína bruta - Tab. 2). Essa diferença deve-se à maior porcentagem de folhas desse tratamento, uma vez que elas apresentaram maior teor de PB $(21,5 \%$ da folha contra $13,1 \%$ do colmo Tab. 2). 


\section{Menezes et al.}

Tabela 1. Médias e erros-padrão para a oferta real de forragem (OF), componentes estruturais da pastagem, massa de forragem (MF), taxa de acúmulo diário (TAD) e carga animal (CA), relacionados com as ofertas de forragem e o fornecimento de suplemento em pastagem de aveia preta

\begin{tabular}{|c|c|c|c|}
\hline \multicolumn{4}{|c|}{ Oferta de forragem } \\
\hline & $6 \%$ & $10 \%$ & Média \\
\hline \multicolumn{4}{|c|}{--- OF Real (kg de MS/100 kg de PV) --- } \\
\hline Com suplemento & $6,08 \pm 0,31$ & $9,07 \pm 0,31$ & $7,58 \pm 0,3$ \\
\hline Sem suplemento & $5,82 \pm 0,31$ & $9,07 \pm 0,31$ & $7,44 \pm 0,3$ \\
\hline Média & $5,95 \pm 0,28 \mathrm{~B}$ & $9,07 \pm 0,28 \mathrm{~A}$ & \\
\hline \multicolumn{4}{|c|}{---\% de folha--- } \\
\hline Com suplemento & $62,1 \pm 3,1$ & $29,1 \pm 3,1$ & $45,6 \pm 2,2$ \\
\hline Sem suplemento & $51,9 \pm 3,1$ & $31,6 \pm 3,1$ & $41,7 \pm 2,2$ \\
\hline Média & $57,0 \pm 2,2 \mathrm{~A}$ & $30,4 \pm 2,2 \mathrm{~B}$ & \\
\hline \multicolumn{4}{|c|}{---\% de colmo--- } \\
\hline Com suplemento & $37,9 \pm 3,1$ & $70,9 \pm 3,1$ & $54,4 \pm 2,2$ \\
\hline Sem suplemento & $48,1 \pm 3,1$ & $68,4 \pm 3,1$ & $58,3 \pm 2,2$ \\
\hline Média & $43,0 \pm 2,2 \mathrm{~B}$ & $69,6 \pm 2,2 \mathrm{~A}$ & \\
\hline \multicolumn{4}{|c|}{---Relação folha/colmo--- } \\
\hline Com suplemento & $1,72 \pm 0,2$ & $0,42 \pm 0,2$ & $1,1 \pm 0,1$ \\
\hline Sem suplemento & $1,18 \pm 0,2$ & $0,47 \pm 0,2$ & $0,8 \pm 0,1$ \\
\hline Média & $1,45 \pm 0,1 \mathrm{~A}$ & $0,45 \pm 0,1 \mathrm{~B}$ & \\
\hline \multicolumn{4}{|c|}{---MF(kg de MS/ha)--- } \\
\hline Com suplemento & $834,93 \pm 86$ & $1225,25 \pm 86,47$ & $1030,24 \pm 129$ \\
\hline Sem suplemento & $665,83 \pm 86$ & $1271,93 \pm 86,47$ & $968,88 \pm 129$ \\
\hline Média & $750,4 \pm 129 B$ & $1248,7 \pm 129 \mathrm{~A}$ & \\
\hline \multicolumn{4}{|c|}{---TAD (kg/ha/dia)--- } \\
\hline Com suplemento & $31,95 \pm 1,06$ & $29,12 \pm 1,06$ & $30,53 \pm 2,12$ \\
\hline Sem suplemento & $36,37 \pm 1,06$ & $27,05 \pm 1,06$ & $31,71 \pm 2,12$ \\
\hline Média & $34,2 \pm 2,1 \mathrm{~A}$ & $28,1 \pm 2,1 \mathrm{~B}$ & \\
\hline \multicolumn{4}{|c|}{---CA (kg de PV/ha)--- } \\
\hline Com suplemento & $1255,05 \pm 82,57$ & $1052,53 \pm 82,57$ & $1153,79 \pm 87,0$ \\
\hline Sem suplemento & $1135,68 \pm 82,57$ & $1099,20 \pm 82,57$ & $1117,44 \pm 87,0$ \\
\hline Média & $1195,4 \pm 87,0$ & $1075,9 \pm 87,0$ & \\
\hline
\end{tabular}

A,B Médias seguidas de letras distintas diferem entre si $(\mathrm{P}<0,05)$ pelo teste de Tukey.

Tabela 2. Médias e erros-padrão dos teores de proteína bruta (PB) dos componentes da pastagem de aveia preta conforme a oferta de forragem e o fornecimento de suplemento

\begin{tabular}{|c|c|c|c|}
\hline \multicolumn{4}{|c|}{ Oferta de forragem } \\
\hline & $6 \%$ & $10 \%$ & Média \\
\hline \multicolumn{4}{|c|}{--- PB, \% - forragem --- } \\
\hline Com suplemento & $22,0 \pm 1,5$ & $13,1 \pm 1,5$ & $17,6 \pm 1,0$ \\
\hline Sem suplemento & $18,0 \pm 1,5$ & $14,1 \pm 1,5$ & $16,0 \pm 1,0$ \\
\hline Média & $20,0 \pm 1,0 \mathrm{~A}$ & $13,6 \pm 1,0 \mathrm{~B}$ & \\
\hline \multicolumn{4}{|c|}{--- PB, \% - folha --- } \\
\hline Com suplemento & $24,8 \pm 1,5$ & $19,0 \pm 1,5$ & $21,9 \pm 1,0$ \\
\hline Sem suplemento & $22,0 \pm 1,5$ & $20,2 \pm 1,5$ & $21,1 \pm 1,0$ \\
\hline Média & $23,4 \pm 1,0 \mathrm{~A}$ & $19,6 \pm 1,0 \mathrm{~B}$ & \\
\hline \multicolumn{4}{|c|}{--- PB, \% - colmo --- } \\
\hline Com suplemento & $17,6 \pm 0,9$ & $10,5 \pm 0,9$ & $14,0 \pm 0,6$ \\
\hline Sem suplemento & $13,0 \pm 0,9$ & $11,1 \pm 0,9$ & $12,0 \pm 0,6$ \\
\hline Média & $15,3 \pm 1,0 \mathrm{~A}$ & $10,8 \pm 1,0 \mathrm{~B}$ & \\
\hline
\end{tabular}

A,B Médias seguidas de letras distintas diferem entre si $(\mathrm{P}<0,05)$ pelo teste Tukey. 
A massa de forragem foi superior $(\mathrm{P}<0,05)$ para oferta de $10 \%$, entretanto com $6 \%$ de oferta, ficou bastante abaixo do preconizado por Mott (1984), que observou que, para espécies temperadas, ela deve estar entre 1.200 e $1.600 \mathrm{~kg}$ de MS/ha, sendo que valores abaixo desses níveis podem comprometer o consumo e reduzir o desempenho. No entanto, não foi observada diferença quanto ao desempenho dos animais nas duas ofertas (Tab. 3), já que os valores de MF podem representar pastagens completamente diferentes em estrutura.

Segundo Carvalho et al. (2001) a variação na densidade, altura e composição para mesma massa de forragem, ou até mesmo massas de forragem diferentes, ocasiona ganho animal semelhante. Além disso, não houve diferença quando foi considerada a massa de lâminas foliares (428,9 contra 359,0kg de MS de LF).

A taxa de acúmulo diária foi maior para oferta de forragem de $6 \%(34,2 \mathrm{~kg}$ de $\mathrm{MS} / \mathrm{ha} / \mathrm{dia}) \mathrm{em}$ relação à oferta de $10 \%(28,1 \mathrm{~kg}$ de $\mathrm{MS} / \mathrm{ha} / \mathrm{dia})$, certamente ocasionada pela maior quantidade de folhas da oferta menor (Tab. 3), ocasionando maior taxa fotossintética. Segundo Jacques (1980), a taxa de acúmulo diária é influenciada pela quantidade de tecido fotossintético remanescente, após o corte, implicando maior ou menor interceptação de luminosidade no rebrote e resultando em diferenças na quantidade de matéria seca acumulada.

A oferta de forragem é uma relação entre disponibilidade (massa de forragem e taxa de acúmulo diário) e carga animal. Como houve diferença na massa de forragem, a carga animal não sofreu influência, uma vez que eram preconizadas ofertas diferentes. Lopes et al. (2008) e Baggio et al. (2009), que regularam a altura da pastagem pela intensidade de pastejo, observaram que os animais intensificam os processos de busca e apreensão em pastos manejados com menor altura e massa de forragem, comprometendo a profundidade e a massa do bocado, componentes essenciais na composição do consumo de matéria seca.

A carga animal juntamente com a massa de forragem são fatores que influenciam nas perdas de pastagens submetidas ao pastejo, ocasionadas no momento de apreensão, pisoteio e senescência das plantas (Hillesheim, 1988). A carga animal está relacionada com o consumo animal, devido ao fato de que, com a presença da suplementação, há a tendência de haver substituição da pastagem pelo suplemento (Freitas et al., 2005), aumentando a capacidade de suporte dela. Porém, a suplementação com $0,8 \%$ do peso vivo de milho moído não foi suficiente para expressar essa diferença, pois a pastagem possuía alto teor proteico e a suplementação energética fornecida provocou um efeito aditivo no ganho médio diário dos animais. Ruas et al. (2000), fornecendo $2 \mathrm{~kg}$ de concentrado por dia para vacas Nelore, observaram que a suplementação não ocasionou efeito substitutivo na pastagem, não aumentando, com isso, a carga animal.

Da mesma forma que ocorreu com as características da pastagem, não houve interação entre oferta e suplementação para as variáveis de desempenho (Tab. 3). A oferta de forragem não influenciou o ganho de peso médio diário (GMD) dos animais. A literatura cita aumento no ganho de peso médio diário com a elevação da altura da pastagem de aveia e azevém (Aguinaga et al., 2006; Lopes et al., 2008). No presente estudo, a oferta de $10 \%$ apresentou altura de $28 \mathrm{~cm}$, e a de $6 \%$ de $16 \mathrm{~cm}$, em média. A falta de diferença entre as ofertas de forragem pode ser explicada pela estrutura da pastagem e qualidade da forragem consumida. $O$ teor de proteína da pastagem (Tab. 2) com $6 \%$ de oferta $(20,0 \%$ de PB) foi superior a de $10 \%(13,6 \%)$, o que compensou a menor oportunidade de seleção.

Delagarde et al. (2001) citam que o desempenho animal depende do nível de ingestão, o qual é determinado, sobretudo, pela oferta de forragem e pela estrutura da pastagem, uma vez que a pastagem com $6 \%$ de OF apresentou maior relação $\mathrm{F} / \mathrm{C}$, tendo, consequentemente, maior qualidade nutricional. Pilau et al. (2005) relataram valores de PB entre 130 e $200 \mathrm{~g} / \mathrm{kg}$ de MS para pastagens de aveia e azevém, de acordo com o período de pastejo com novilhas de corte em recria. Segundo o valor estabelecido no NRC (1984) para a recria de novilhos de corte $(129 \mathrm{~g} / \mathrm{kg}$ de MS), o teor de PB das pastagens de ambos os tratamentos permite expressar, para esta categoria, o máximo ganho de peso. 
Tabela 3. Médias e erros-padrão para o ganho médio diário (GMD), ganho de peso vivo por hectare (GPV/ha) e ganho de peso vivo por dia (GPV/dia) de acordo com a oferta de forragem e com o fornecimento de suplemento em 60 dias de pastejo de aveia preta

\begin{tabular}{|c|c|c|c|}
\hline & \multicolumn{2}{|c|}{ Oferta de forragem } & \multirow[b]{2}{*}{ Média } \\
\hline & $6 \%$ & $10 \%$ & \\
\hline \multicolumn{4}{|c|}{--- GMD (kg/dia) --- } \\
\hline Com suplemento & $0,707 \pm 0,08$ & $0,791 \pm 0,08$ & $0,749 \pm 0,05 \mathrm{~A}$ \\
\hline Sem suplemento & $0,675 \pm 0,07$ & $0,513 \pm 0,08$ & $0,594 \pm 0,05 \mathrm{~B}$ \\
\hline Média & $0,691 \pm 0,05$ & $0,652 \pm 0,06$ & \\
\hline \multicolumn{4}{|c|}{--- GPV/ha (kg/ha) --- } \\
\hline Com suplemento & $242,1 \pm 20,1$ & $207,6 \pm 20,1$ & $224,8 \pm 14,1$ \\
\hline Sem suplemento & $198,3 \pm 20,1$ & $175,9 \pm 20,1$ & $187,1 \pm 14,1$ \\
\hline Média & $220,2 \pm 14,1$ & $191,7 \pm 14,1$ & \\
\hline \multicolumn{4}{|c|}{--- GPV/dia (kg/ha/dia) --- } \\
\hline Com suplemento & $4,30 \pm 0,3$ & $3,55 \pm 0,3$ & $3,93 \pm 0,2$ \\
\hline Sem suplemento & $3,40 \pm 0,3$ & $3,00 \pm 0,3$ & $3,20 \pm 0,2$ \\
\hline Média & $3,85 \pm 0,2$ & $3,28 \pm 0,2$ & \\
\hline
\end{tabular}

A,B Médias seguidas de letras distintas diferem entre si $(\mathrm{P}<0,05)$ pelo teste Tukey.

Observa-se, ainda, na Tab. 3, que a suplementação melhorou o GMD. Apesar de a literatura indicar que a presença de suplementação pode ocasionar aumento de até $70 \%$ no desempenho (Pilau et al., 2005), houve aumento de 26,09\% no GMD com a presença do suplemento na dieta. A suplementação energética proporcionou um efeito aditivo no consumo de matéria seca, onde os animais não substituíram a pastagem pelo suplemento, uma vez que houve semelhança na carga animal dos tratamentos (Tab. 1). Frizzo et al. (2003) observaram que quanto maior o nível de suplementação, menor será o consumo de forragem. No entanto, no presente estudo, isso não ocorreu, provavelmente, em consequência do desbalanço nutricional causado pela maior participação na dieta do suplemento com reduzido teor de nitrogênio.

A maior parte da proteína verdadeira das espécies forrageiras é degradada no rúmen e transformada em proteína microbiana (Poppi e Mclennan, 1995). O grão de milho participa na dieta de animais em pastagem com alto teor proteico como fornecedor de carbono para os microrganismos, uma vez que há excesso de nitrogênio no rúmen, proveniente da forragem consumida. A suplementação, nesta condição, melhora a eficiência de utilização do $\mathrm{N}$ da forragem, por fornecer ao animal maior aporte de aminoácidos, por meio da proteína não degradada no rúmen, e reduzir as perdas de $\mathrm{N}$ no rúmen como NH4 (Elizalde et al., 1999).

O ganho de peso vivo (GPV) total/ha e o GPV/ha/dia não sofreram influência dos tratamentos. Lopes et al. (2008) observaram resposta linear negativa do GPV/ha com a altura da pastagem. Esses autores justificam a diferença pela maior carga animal nas pastagens de menor altura. No entanto, no presente estudo, não houve diferença para a carga animal entre as ofertas de forragem. Trabalhando com o mesmo cultivar de aveia do presente estudo (IPR-61), Grise et al. (2002) também não encontraram diferença para o GPV/ha.

\section{CONCLUSÕES}

Pastagens de aveia preta IPR 61 manejada com $6 \%$ de oferta de forragem apresentam melhor estrutura (relação folha/colmo), maior taxa de crescimento e, consequentemente, melhor qualidade nutricional. A suplementação energética em pastagem de aveia traz vantagens quanto ao desempenho de bezerros na fase de recria por meio do efeito aditivo. 


\section{REFERÊNCIAS}

AGUINAGA, A.A.Q.; CARVALHO, P.C.F.; ANGHINONI, I. et al. Produção de novilhos superprecoces em pastagem de aveia e azevém submetida a diferentes alturas de manejo. Rev. Bras. de Zootec., v.35, p.1765-1773, 2006.

ANUÁRIO BRASILEIRO DA PECUÁRIA ANUALPEC, São Paulo: $F N P$ - Consultoria $e$ Comércio, 2011

ASSOCIATION OF OFFICIAL ANALYTICAL CHEMISTS - AOAC. Official methods of analysis. 14.ed. Washington, D.C.: 1984. 1141p.

BAGGIO, C.; CARVALHO, P.C.F.; SILVA, J.L. et al. Padrões de deslocamento e captura de forragem por novilhos em pastagem de azevémanual e aveia-preta manejada sob diferentes alturas em sistema de integração lavourapecuária. Rev. Bras. Zootec., v.38, p.215-222, 2009.

CARVALHO, P.C.F.; RIBEIRO FILHO, H.M.N.; POLI, C.H.E.C. et al. Importância da estrutura da pastagem na ingestão e seleção de dietas de animais pelo animal em pastejo. In: MANEJO SUSTENTÁVEL EM PASTAGEM, 1, 2005, Maringá. Anais... Maringá: SBZ, 2001. (CD-ROM)

DELAGARDE, R.; PRACHE, S.; D'HOUR, P. et al. Ingestion de l'herbe par les ruminants au pâturage. Fourrages, v.166, p.189-212, 2001.

ELIZALDE, J.C.; MERCHEN, R.N.; FAULKNER, D.B. Supplemental cracked corn for steers fed fresh alfafa.2. Protein and amino acid digeston. J. An. Sci., v.77, p.467-475, 1999.

EUCLIDES, V.P.B. Produção intensiva de carne bovina em pasto. In: SIMPÓSIO DE PRODUÇÃO DE GADO DE CORTE, 2, 2001, Viçosa. Anais... Viçosa: Universidade Federal de Viçosa, p.55-82, 2001.

FRIZZO, A.; ROCHA, M.G.; RESTLE, J. Produção de forragem e retorno econômico da pastagem de aveia e azevém sob pastejo com bezerras de corte submetidas a níveis de suplementação energética. Rev. Bras. Zootec., v.32, p.632-642, 2003.
FREITAS, F.K.; ROCHA, M.G.; RESTLE, J. et al. Suplementação Energética na Recria de Fêmeas de Corte em Pastagem Cultivada de Inverno. Produção Animal. Rev. Bras. Zootec., v.34, p.1256-1266, 2005.

GIBB, M.J.; TREACHER, T.T. The effect of herbage allowance on herbage intake and performance of lambs grazing perennial ryegrass and red clover swards. J. Agric. Sci., v.86, p.355365, 1976.

GRISE, M.M.; CECATO, U.; MORAES, A. et al. Avaliação do Desempenho Animal e do Pasto na Mistura Aveia IAPAR 61 (Avena strigosa Schreb) e Ervilha Forrageira (Pisum arvense L.) Manejada em Diferentes Alturas. Rev. Bras. Zootec., v.31, p.1085-1091, 2002.

HILLESHEIM, A.H. Manejo do gênero Pennisetum sob pastejo. In: SIMPÓSIO SOBRE MANEJO DA PASTAGEM, 9, 1998, Piracicaba. Anais... Piracicaba: Fundação de Estudos Agrários "Luiz de Queiroz", 77 - 1081988.

HOLMES, C.W. Pastures for dairy cows. In: Livestock feeding on pasture. New Zealand Society of Animal Production, n.10, p.133-43, 1987. (Occasional Publication)

JACQUES, A.V.A. Fundamentos de manejo de plantas forrageiras, área foliar e reservas orgânicas. In: SEMINÁRIO SOBRE PASTAGENS "De que pastagens necessitamos", Porto Alegre: FARSUL,p.140-157, 1980.

KLINGMAN, D.L.; MILES, S.R.; MOTT, G.O. The cage method for determining consumption and yield of pasture herbage. J. Am. Soc. Agr., v.35, p.739-746, 1943.

LOPES, M.L.T.; CARVALHO, P.C.F.; ANGHINONI, I. et al. Sistema de integração lavoura-pecuária: desempenho e qualidade da carcaça de novilhos superprecoces terminados em pastagem de aveia e azevém manejada sob diferentes alturas. Cienc. Rural, v.38, p.178-184, 2008.

MOTT, G.O. Grazing pressures and the measurement of pastures production. In: INTERNATIONAL GRASSLAND CONGRESS, 8, 1960, Reading. Proceedings... Lexington: American Forage and Grassland Council, p.373377.1984. 
MOTT, G.O.; LUCAS, H.L. The design, conduct and interpretation of grazing trials on cultivated and improved pastures. In: INTERNATIONAL GRASSLAND CONGRESS, 6, 1952, Pensylvania. Proceedings... Pensylvania: SCP, p.1380-1395, 1952.

NUTRIENT requirement of beef cattle. 6.ed. Washington, D.C.: National Academy Press, 1984. 90p.

NUTRIENT requirement of beef cattle. 7.ed. Washington: National Academic Press, 242p, 1996.

PILAU, A.; ROCHA M.G.; RESTLE, J. et al. Desenvolvimento de novilhas de corte recebendo ou não suplementação energética em pastagem com diferentes disponibilidades de forragem. Rev. Bras. Zootec., v.34, p.1483-1492, 2005.

POPPI, D.P.; McLENNAN, S.R. Protein and energy utilization by ruminants at pasture. $J$. Anim. Sci., v.73, p.278-290, 1995.
REIS, R.A.; RUGGIERI, A.C.; CASAGRANDE, D.R. et al. Suplementação da dieta de bovinos de corte como estratégia do manejo das pastagens. Rev. Bras. Zootec., v.38, p.147-159, 2009.

RUAS, J.R.M.; TORRES, C.A.A.; VALADARES FILHO, S.C. et al. Efeito da Suplementação Proteica a Pasto sobre Consumo de Forragens, Ganho de Peso e Condição Corporal, em Vacas Nelore. Rev. Bras. Zootec., v.29, p.930-934, 2000.

SANTOS, D.T.; ROCHA, M.G.; QUADROS, F.L.F. et al. Suplementos energéticos para recria de novilhas de corte em pastagens anuais. Desempenho animal. Rev. Bras. Zootec., v.34, p.209-219, 2005.

SAS INSTITUTE. SAS/STAT user's guide: statistics. 4.ed. Version 6, Cary: v.2, 2001.

WILM, H.G.; COSTELlO, D.F.; KLIPPLE, G.E. Estimating forage yield by the doublesampling methods. J. Am. Soc. Agr., v.36, p.194203, 1944. 